\title{
Matrix Formulation of Foundations for Vibrating Machinery in Frequency Domain
}

\section{Formulación matricial de cimentaciones para maquinaria vibratoria en el dominio de la frecuencia}

\author{
Carbajal-Romero M.F. \\ Sección de Estudios de Posgrado ESIME Azcapotzalco \\ Instituto Politécnico Nacional. México DF \\ E-mail:mcarbajalr@ipn.mx \\ Rodríguez-Castellanos A. \\ Instituto Mexicano del Petróleo. México DF \\ E-mail:arcastel@imp.mx \\ Rodríguez-Sánchez J.E. \\ Instituto Mexicano del Petróleo. México DF \\ E-mail:ersanche@imp.mx \\ Flores-Méndez E. \\ Sección de Estudios de Posgrado ESIA Zacatenco \\ Instituto Politécnico Nacional. México DF \\ E-mail:efloresm@ipn.mx
}

(Recibido: agosto de 2008; aceptado: febrero de 2010)

\begin{abstract}
A matrix formulation to study the coupled response of rigid foundations modelled by springs and dashpots is presented. Springs and dashpots orientation can be any possible, thus a general solution is determined. Response in terms of displacements and rotations is determined from a matrix system in the complex field. The physics of the problem presented here has been extensively studied and a broad range of useful formulas to determine springs and dashpots properties in soil-structure interaction is available, however it has also been identified that there are some limitations on coupling various degrees of freedom in the available formulations. Then, the novelty of the approach presented comes from the matrix manipulation that leads to an expression that provides a closer approximation to the real phenomenon, because all degrees of freedom can be coupled. This approach may allow to the analyst finding a coupled response including the cases when either springs or dashpots are not orthogonally oriented. In an example at the end of this study, the influence of one of the involved parameters in the soil-structure analysisis point ed out.
\end{abstract}

Keywords: Springs, dashpots, rigidbody, coupled analysis, frequency domain. 
DOI: http://dx.doi.org/10.22201/fi.25940732e.2010.11n3.024

Matrix Formulation of Foundations for Vibrating Machinery in Frequency Domain

\begin{abstract}
Resumen
Se presenta una formulación matricial para el estudio de la respuesta acoplada de cimentaciones rígidas, dicha matriz se modela con resortes y amortiguadores. Los resortes y amortiguadores pueden ser orientados arbitrariamente, de ahí que esta formulación tenga un carácter general. La respuesta en términos de desplazamientos y de rotaciones se determina a partir de un sistema matricial en el campo complejo. La física del problema aquí presentado se ha estudiado extensivamente y existe una amplia gama de fórmulas útiles para determinar las características de los resortes y de los amortiguadores en la interacción suelo-estructura; sin embargo, también se han identificado algunas limitantes en referencia al acoplamiento de los grados de libertad en las formulaciones encontradas. Entonces, la novedad del planteamiento matemático presentado viene dada por la manipulación matricial que conduce a una expresión que proporciona una aproximación más cercana al fenómeno real, dado que todos los grados de libertad pueden ser acoplados. Esta propuesta puede permitirle al analista encontrar una respuesta acoplada incluyendo aquellos casos donde los resortes y/o los amortiguadores no están orientados ortogonalmente. Al final de este estudio, se incluye un ejemplo de aplicación donde se enfatiza la importancia de uno de los parámetros involucrados en el análisis de interacción suelo-estructura.
\end{abstract}

Descriptores: resortes, amortiguadores, cuerpo rígido, análisis acoplado, dominio de la frecuencia.

\section{Introduction}

Some of the present problems in the field of dynamics of structures are those related to the response of rigid foundations under dynamic loadings. Usually, the analysis of these structures is carried out considering lumped parameter methods, where the soil is replaced by a system of frequency-dependent springs and dashpots.

In many available formulations, the analysis of the foundation-soil system may be done considering an uncoupled system, where only in plane responses are determined. It is well-known that a foundation-soil system has six degrees of freedom in an orthogonal reference system.

Expressions for calculating springs and dashpots for the six degrees of freedom can be obtained from several published references. We refer the reader to see the pioneering works of Richards et al. (1970), Luco (1982), Gazetas (1983, 1991), Dobry and Gazetas (1985, 1986) and Pais and Kausel (1988). And more recent works related with lumped springs and dashpots for foundation analysis can be consulted in Wu and Chen (2002), Wu and Lee (2004) and Wolf and Paronesso (2007). A good reference to design rigid foundations under dynamic loading is Bowles (1996). Recent results for springs and dashpots in layered media can be seen in Wolf and Deeks (2004).
Determining expressions for springs and dashpots is not within the scope of the present work. A matrix formulation in which springs and dashpots are gathered for six degrees of freedom is proposed, so a coupled response, for springs and dashpots acting simultaneously is obtained.

\section{Equation of motion}

The general equation of motion, in time domain, for a rigid body system can be expressed as:

$$
[M] \ddot{a}(t)+[C] \dot{a}(t)+[K] a(t)=\bar{F}(t),
$$

where,

$$
\begin{aligned}
& {[M]=\text { Mass matrix }} \\
& {[K]=\text { Stiffness matrix }} \\
& {[C]=\text { Damping matrix }} \\
& a(t)=\text { Displacement vector } \\
& \dot{a}(t)=\text { Speed vector } \\
& \ddot{a}(t)=\text { Acceleration vector and } \\
& \bar{F}(t)=\text { Force vector. }
\end{aligned}
$$

Expressing the displacement and force vectors in frequency domain, one has

$$
a(t)=a(\omega) e^{i \omega t}
$$




$$
\bar{F}(t)=\bar{F}(\omega) e^{i \omega t}
$$

After calculating speed and acceleration vectors using equation (2) and arranging common terms, we finally express equation (1), in frequency domain, as:

$$
\left\{-\omega^{2}[M]+i \omega[C]+[K]\right\} a(\omega)=\bar{F}(\omega)
$$

The solution for equation (4) is given by

$$
a(\omega)=\left\{-\omega^{2}[M]+i \omega[C]+[\mathrm{K}]\right\}^{-1} \bar{F}(\omega)
$$

Equation (5) is the solution, in frequency domain, for a rigid body system, which contains six degrees of freedom. Mass, damping and stiffness matrixes are presented in the following sections.

\section{Stiffness matrix}

Let us rename the displacement vector as

$\{d\}=\left\{d_{x}, d_{y}, d_{z}, \theta_{x}, \theta_{v}, \theta_{z}\right\}^{T}$ or $\{d\}=\{\bar{d}, \bar{\theta}\}^{T}$, where $\bar{d}=\left\{d_{x}, d_{y}, d_{z}\right\}^{T}$ and $\bar{\theta}=\left\{\theta_{x}, \theta_{y}, \theta_{z}\right\}^{T}$. When a rigid body experiences a small rotation, see figure $1 \mathrm{a}$, displacement of the sprig $K_{i}$ due to that rotation can be expressed as $d \bar{r}_{i}=\bar{\theta} \times \bar{r}_{i}$, where $\bar{\theta}=\left\{\theta_{x}, \theta_{y}, \theta_{z}\right\}^{T}$ is the rotation vector and $\bar{r}_{i}$ is the position vector of spring $K_{i}$.

Considering that $\eta_{i}=\left\{\alpha_{i}, \beta_{i}, \gamma_{i}\right\}$ represents the spring vector of director cosines of the spring $K_{i}$, total displacement of spring $K_{i}$ is given by

$$
\delta_{i}=\bar{\eta}_{i} \cdot\left[\bar{d}+\bar{\theta} \times \bar{r}_{i}\right]
$$

Thus, the force in the spring is

$$
\bar{F}_{i}=\bar{\eta}_{i} \cdot\left[\bar{d}+\bar{\theta} \times \bar{r}_{i}\right] \bar{\eta}_{i} K_{i}
$$

and the moment is

$$
M_{i}=\bar{r}_{i} \times \bar{F}_{i}
$$

The product $\bar{\theta} \times \bar{r}_{i}$ in matrix terms is $[r] \bar{\theta}$, where $[r]$ is the springs position matrix given as

$$
[r]=\left[\begin{array}{ccc}
0 & Z_{i} & -Y_{i} \\
-Z_{i} & 0 & X_{i} \\
Y_{i} & -X_{i} & 0
\end{array}\right] .
$$

Force in the spring can be expressed as follows

$$
\begin{aligned}
& \bar{F}_{i}=K_{i}\left(\bar{\eta}_{i} \cdot \bar{d}\right) \bar{\eta}_{i}+\left(\bar{\eta}_{i} \cdot[r] \bar{\theta}\right) \bar{\eta}_{i} K_{i} \\
& \bar{F}_{i}=K_{i}\left(\bar{\eta}_{i}^{T} \bar{d}\right) \bar{\eta}_{i}+K_{i}\left(\bar{\eta}_{i}^{T}[r] \bar{\theta}\right) \bar{\eta}_{i} \\
& \bar{F}_{i}=K_{i}\left(\bar{\eta}_{i} \bar{\eta}_{i}^{T}\right) \bar{d}+K_{i}\left(\bar{\eta}_{i} \bar{\eta}_{i}^{T}\right)[r] \bar{\theta}
\end{aligned}
$$

and the moment is as

$$
\begin{aligned}
& M_{i}=\bar{r}_{i} \times \bar{F}_{i}=[r]^{T} \bar{F}_{i} \\
& M_{i}=K_{i}[r]^{T}\left(\bar{\eta}_{i} \bar{\eta}_{i}^{T}\right) \bar{d}+K_{i}[r]^{T}\left(\bar{\eta}_{i} \bar{\eta}_{i}^{T}\right)[r] \bar{\theta}
\end{aligned}
$$

Expressing equations (12) and (14) in matrix form,

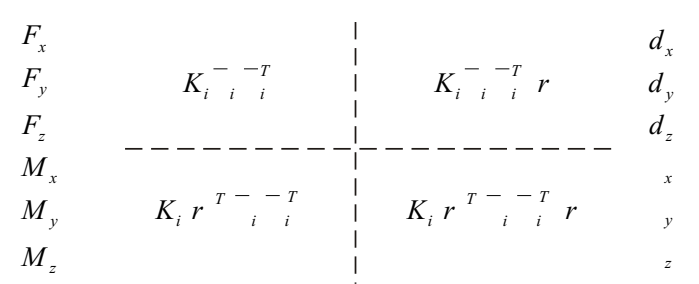

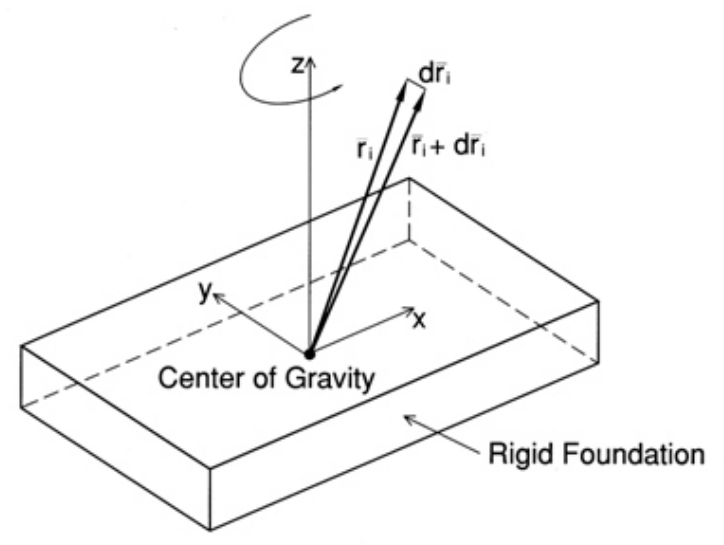

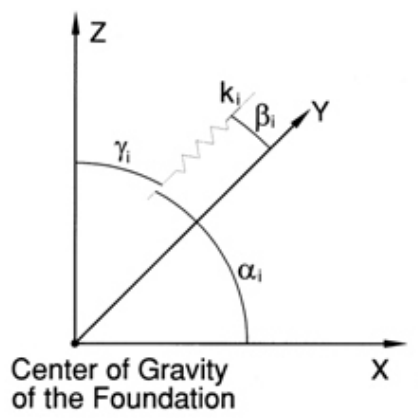

Figure 1. a) Rotation of a rigid body; b) A spring $K_{i}$ in the reference system 


$$
\left\{\begin{array}{l}
F \\
M
\end{array}\right\}=\left[\begin{array}{ll}
K_{d d} & F_{d \theta} \\
K_{\theta d} & K_{\theta \theta}
\end{array}\right]\left\{\begin{array}{l}
d \\
\theta
\end{array}\right\}
$$

or in its compact form, the well-known expression of $\{F\}=[K]\{d\}$, where $[K]$ is the general stiffness matrix. Equation (15) or (16) represents the system with its six degrees of freedom that describes the coupled response of a rigid foundation supported by springs.
Developing the stiffness matrix of equation (15), one has in the equation (17).

Rotational springs should be added directly to sub matrix $K_{\theta \theta}$. Assuming orthogonal orientation of the springs, as shown in figure 2 , stiffness matrix of equation (17) can be simplified. Therefore, $K_{\mathrm{vz}}, K_{\mathrm{hx}}$ and $K_{\mathrm{hy}}$, represent vertical and horizontal springs, respectively. Coordinates and director cosines for each sprig are shown in table 1.

\begin{tabular}{|c|c|c|c|c|c|}
\hline$\left[\alpha_{i}^{2}\right.$ & $\alpha_{i} \beta_{i}$ & $\alpha_{i} \gamma_{i}$ & $-\alpha_{i} \beta_{i} Z_{i}+\alpha_{i} \gamma_{i} Y_{i}$ & $\alpha_{i}^{2} Z_{i}-\alpha_{i} \gamma_{i} X_{i}$ & $-\alpha_{i}^{2} Y_{i}+\alpha_{i} \beta_{i} X_{i}$ \\
\hline$\alpha_{i} \beta_{i}$ & $\beta_{i}^{2}$ & $\beta_{i} \gamma_{i}$ & $-\beta_{i}^{2} Z_{i}+\beta_{i} \gamma_{i} Y_{i}$ & $\alpha_{i} \beta{ }_{i} Z_{i}-\beta_{i} \gamma_{i} X_{i}$ & $-\alpha_{i} \beta_{i} Y_{i}+\beta_{i}^{2} X_{i}$ \\
\hline$\alpha_{i} \gamma_{i}$ & $\beta_{i} \gamma_{i}$ & $\gamma_{i}^{2}$ & $-\beta_{i} \gamma_{i} Z_{i}+\gamma_{i}^{2} Y_{i}$ & $\alpha_{i} \gamma_{i} Z_{i}-\gamma_{i}^{2} X_{i}$ & $-\alpha_{i} \gamma_{i} Y_{i}+\beta_{i} \gamma_{i} X_{i}$ \\
\hline$-\alpha_{i} \beta_{i} Z_{i}+\alpha_{i} \gamma_{i} Y_{i}$ & $-\beta_{i}{ }^{2} Z_{i}+\beta_{i} \gamma_{i} Y_{i}$ & $-\beta_{i} \gamma_{i} Z_{i}+\gamma_{i}{ }^{2} Y_{i}$ & $\left(-\beta_{i} Z_{i}+\gamma_{i} Y_{i}\right)^{2}$ & $\begin{array}{l}\left(\alpha_{i} Z_{i}-\alpha_{i} X_{i}\right)^{*} \\
\left(-\beta_{i} Z_{i}+\gamma_{i} Y_{i}\right)\end{array}$ & $\begin{array}{l}\left(-\alpha_{i} Y_{i}+\beta_{i} X_{i}\right)^{*} \\
\left(\gamma_{i} Y_{i}-\beta_{i} Z_{i}\right)\end{array}$ \\
\hline$\alpha_{i}^{2} Z_{i}+\alpha_{i} \gamma_{i} X_{i}$ & $\alpha_{i} \beta_{i} Z_{i}-\beta{ }_{i} \gamma_{i} X_{i}$ & $\alpha_{i} \gamma_{i} Z_{i}-\gamma_{i}^{2} X_{i}$ & $\begin{array}{l}\left(\alpha_{i} Z_{i}-\alpha_{i} X_{i}\right)^{*} \\
\left(-\beta_{i} Z_{i}+\gamma_{i} Y_{i}\right)\end{array}$ & $\left(\alpha_{i} Z_{i}-\gamma_{i} X_{i}\right)^{2}$ & $\begin{array}{l}\left(-\alpha_{i} Y_{i}+\beta_{i} X_{i}\right)^{*} \\
\left(\alpha_{i} Z_{i}-\gamma_{i} X_{i}\right)\end{array}$ \\
\hline$-\alpha_{i}^{2} Y_{i}+\alpha_{i} \beta_{i} X_{i}$ & $-\alpha_{i} \beta_{i} Y_{i}+\beta_{i}^{2} X_{i}$ & $-\alpha_{i} \gamma_{i} Y_{i}+\beta_{i} \gamma_{i} X_{i}$ & $\begin{array}{l}\left(-\alpha_{i} Y_{i}+\beta_{i} X_{i}\right)^{*} \\
\left(\gamma_{i} Y_{i}-\beta_{i} Z_{i}\right)\end{array}$ & $\begin{array}{l}\left(-\alpha_{i} Y_{i}+\beta_{i} X_{i}\right)^{*} \\
\left(\alpha_{i} Z_{i}-\gamma_{i} X_{i}\right)\end{array}$ & $\left(-\alpha_{i} Y_{i}+\beta_{i} X_{i}\right)^{2}$ \\
\hline
\end{tabular}

a)

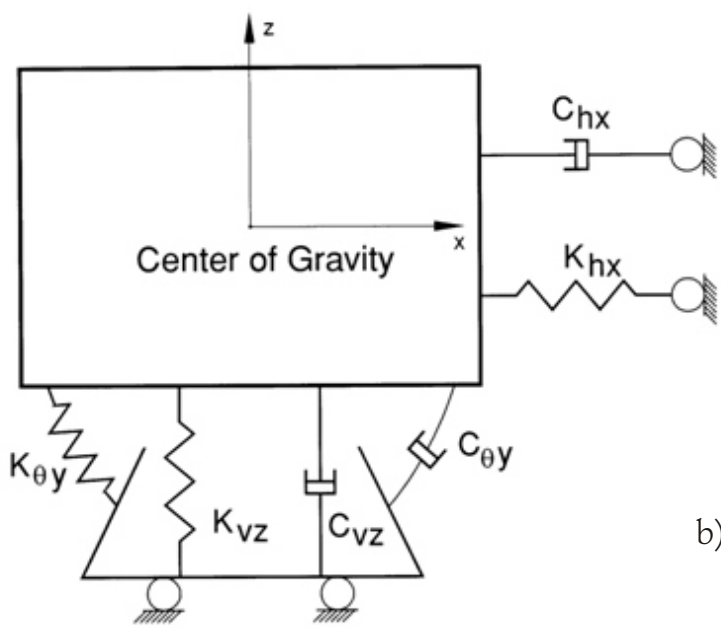

b)

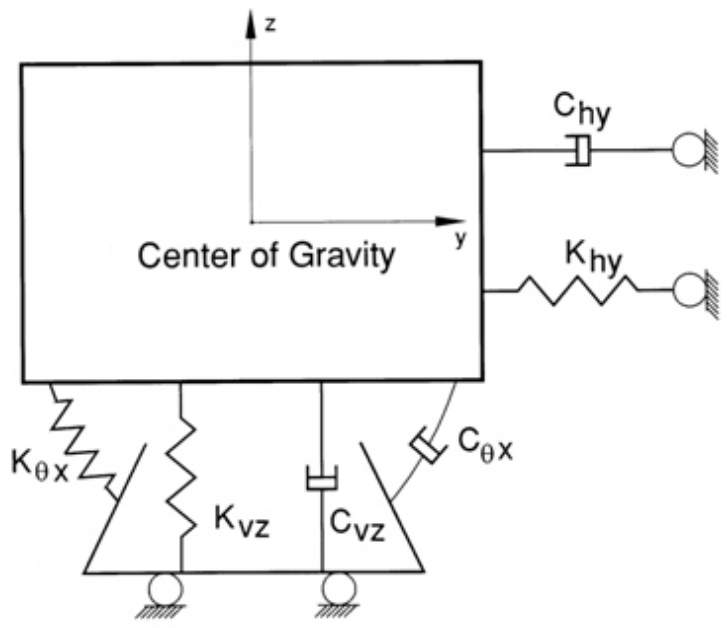

Figure 2. Orthogonal orientation of springs 
DOI: http://dx.doi.org/10.22201/fi.25940732e.2010.11n3.024

Carbajal-Romero M.F., Rodríguez-Castellanos A., Rodríguez-Sánchez J.E. and Flores-Méndez E.

Table 1. Coordinates and director cosines for orthogonal orientation of springs

\begin{tabular}{ccccccc}
\hline Spring & $\alpha_{i}$ & $\beta_{i}$ & $\gamma_{i}$ & $X_{i}$ & $Y_{i}$ & $Z_{i}$ \\
\hline$K_{h x}$ & 1 & 0 & 0 & $X_{h x}$ & $Y_{h x}$ & $Z_{h x}$ \\
$K_{h y}$ & 0 & 1 & 0 & $X_{h y}$ & $Y_{h y}$ & $Z_{h y}$ \\
$K_{v z}$ & 0 & 0 & 1 & $X_{v z}$ & $Y_{v z}$ & $Z_{v z}$ \\
$K_{\theta x}$ & 1 & 0 & 0 & 0 & 0 & 0 \\
$K_{\theta y}$ & 0 & 1 & 0 & 0 & 0 & 0 \\
$K_{\theta z}$ & 0 & 0 & 1 & 0 & 0 & 0 \\
\hline
\end{tabular}

Stiffness matrix for each spring can be expressed as shown in equations (18), (19) and (20) for springs in "X", "Y" and "Z" directions, respectively.

$$
K_{h x}\left[\begin{array}{cccccc}
1 & 0 & 0 & 0 & Z_{h x} & -Y_{h y} \\
0 & 0 & 0 & 0 & 0 & 0 \\
0 & 0 & 0 & 0 & 0 & 0 \\
0 & 0 & 0 & 0 & 0 & 0 \\
Z_{h x} & 0 & 0 & 0 & Z_{h x}{ }^{2} & -Z_{h x} Y_{h x} \\
-Y_{h x} & 0 & 0 & 0 & -Y_{h x} Z_{h x} & Y_{h x}{ }^{2}
\end{array}\right]
$$

$$
K_{h y}\left[\begin{array}{cccccc}
0 & 0 & 0 & 0 & Z_{h x} & 0 \\
0 & 1 & 0 & -Z_{h y} & 0 & X_{h y} \\
0 & 0 & 0 & 0 & 0 & 0 \\
0 & -Z_{h y} & 0 & Z_{h y}^{2} & 0 & -Z_{h y} X_{h y} \\
0 & 0 & 0 & 0 & 0 & 0 \\
0 & X_{h y} & 0 & -Z_{h y} X_{h y} & 0 & Y_{h y}^{2}
\end{array}\right]
$$

$$
K_{v z}\left[\begin{array}{cccccc}
0 & 0 & 0 & 0 & 0 & 0 \\
0 & 0 & 0 & 0 & 0 & 0 \\
0 & 0 & 1 & Y_{v z} & -X_{v z} & 0 \\
0 & 0 & Y_{v z} & Y_{v z}{ }^{2} & -X_{v z} Y_{v z} & 0 \\
0 & 0 & -X_{v z} & -X_{v z} Y_{v z} & X_{v z}{ }^{2} & 0 \\
0 & 0 & 0 & 0 & 0 & 0
\end{array}\right]
$$

\section{Rotational springs}

Rotational springs are added directly to the stiffness sub-matrix $k_{\theta \theta}$, which is a part of the stiffness matrix. Sub-matrix $k_{\theta \theta}$ is, equation (21).

$$
\left[\begin{array}{ccc}
K_{\theta x} & 0 & 0 \\
0 & K_{\theta y} & 0 \\
0 & 0 & K_{\theta z}
\end{array}\right]
$$

\section{Complete stiffness matrix}

The complete stiffness matrix referenced to the orthogonal system is obtained adding the stiffness sub-matrixes, for the lineal and rotational springs, given in equations (18) to (21). Therefore, the whole stiffness matrix of the system can be represented as in equation (22). 


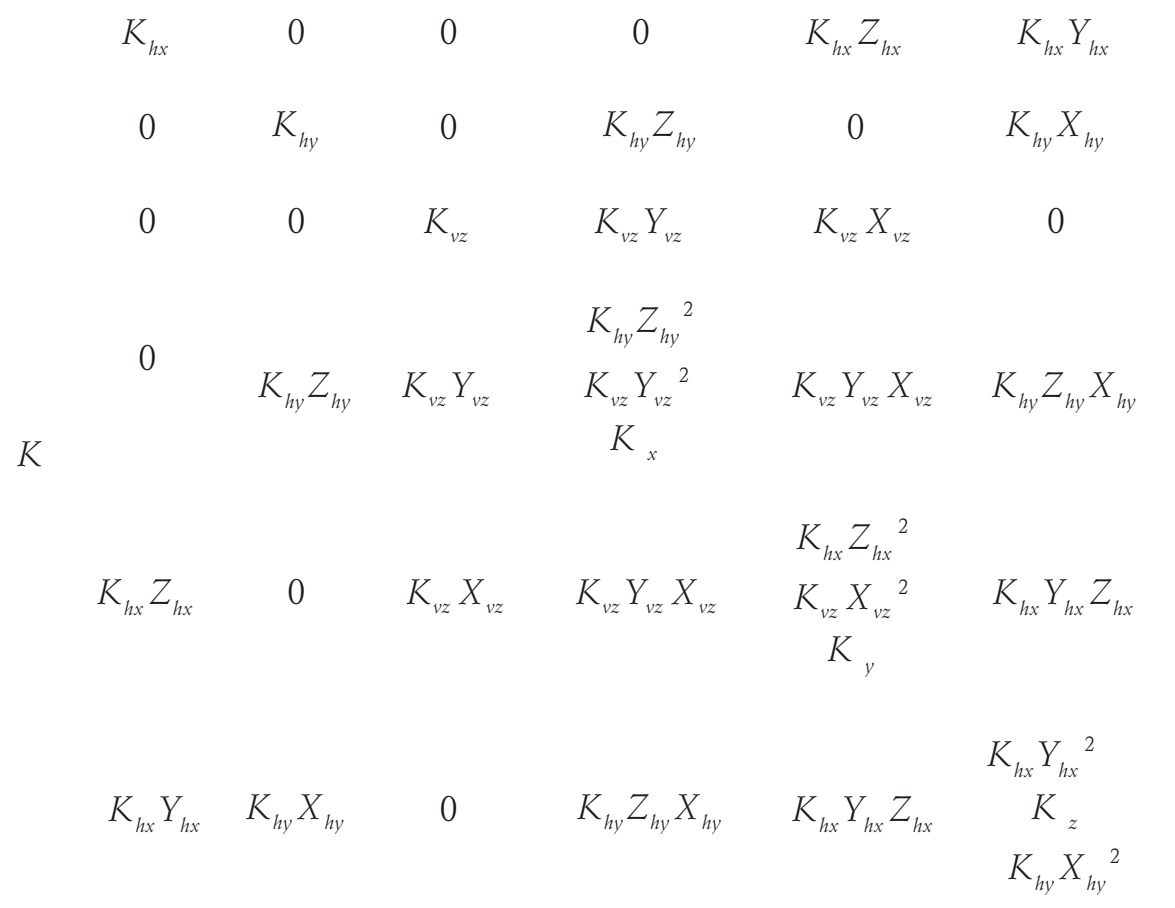

\section{Damping matrix}

Similarly as the stiffness matrix was formed, and considering that the dashpots are orthogonally oriented, the complete damping matrix is as in equation (23).

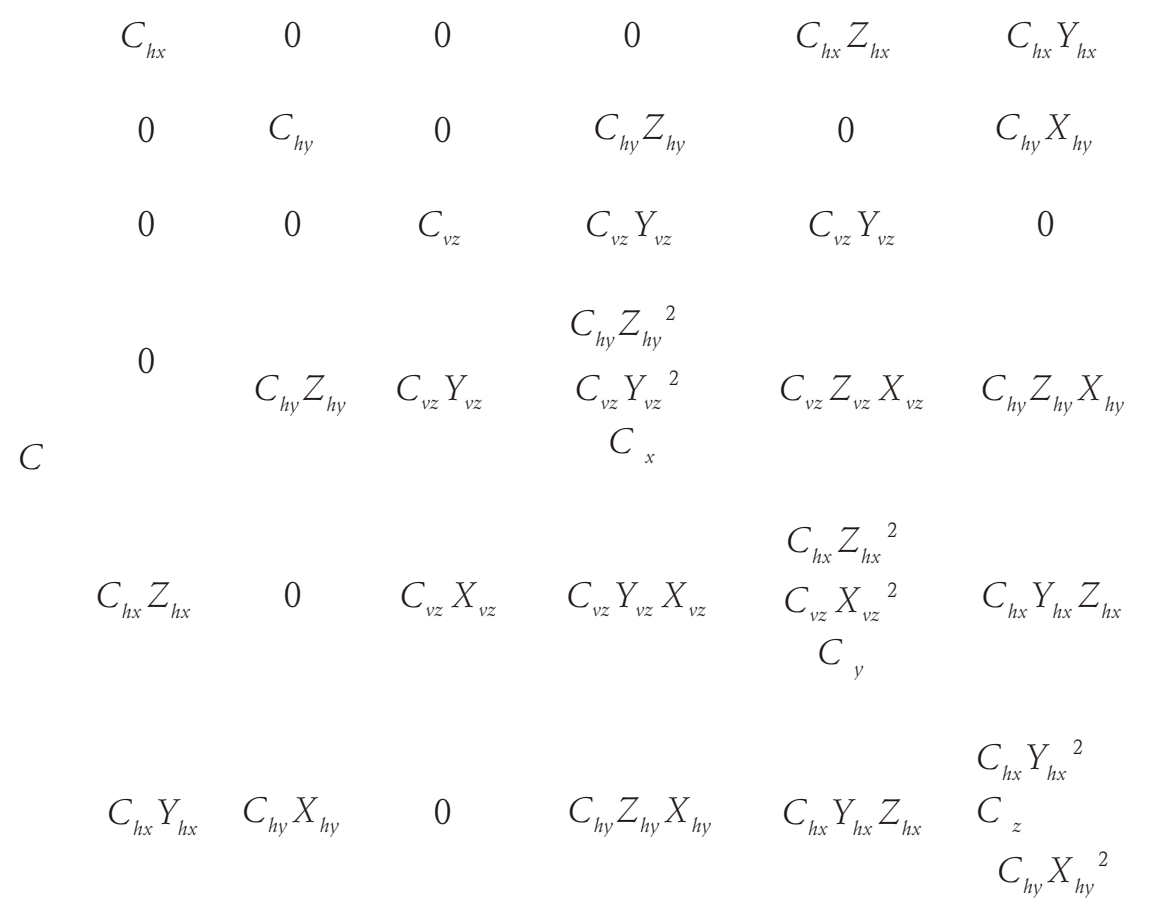


DOI: http://dx.doi.org/10.22201/fi.25940732e.2010.11n3.024

Carbajal-Romero M.F., Rodríguez-Castellanos A., Rodríguez-Sánchez J.E. and Flores-Méndez E.

\section{Mass matrix and force vector}

For the system formed by the rigid body, springs and dashpots, the mass matrix can be as in equation (24).

$M=\left[\begin{array}{ccc}m & 0 & 0 \\ 0 & m & 0 \\ 0 & 0 & m \\ 0 & 0 & 0 \\ 0 & 0 & 0 \\ 0 & 0 & 0\end{array}\right.$

where, $m=$ mass of the instrument or equipment on the foundation, $B=$ half-width of the foundation, $L=$ halflength of the foundation, $A=$ height of the instrument or equipment.

\section{Force vector}

The equipment supplier usually gives the force vector in the domain frequency. A general expression for the force vector is given by $\bar{F}=\left\{F_{x}, F_{y}, F_{z}, M_{x}, M_{y}, M_{z}\right\}^{T}$, where:

$$
\begin{aligned}
& F_{x}=\text { horizontal force in " } X \text { " direction, } \\
& F_{y}=\text { horizontal force in "Y" direction, } \\
& F_{z}=\text { vertical force in " } Z \text { " direction, } \\
& M_{x}=\text { moment around " } X \text { " axis, } \\
& M_{y}=\text { moment around " } Y \text { " axis and } \\
& M_{z}=\text { moment around " } Z \text { " axis. }
\end{aligned}
$$

\section{Numerical example}

In this section we used the formulation previously developed in order to show the influence that one of the important factors has in the analysis and design of rigid foundations. This factor is the depth of embedment. For simplicity reasons we do not present results related to the influence on the response neither of soil internal damping nor of shear modulus.

$\bar{K}$ and $\bar{C}$ are functions of frequency $\omega$, soil properties and area "Ac" of contact between soil and foundations. Other parameters required are: dimensions $2 \mathrm{~L}$ and $2 \mathrm{~B}$ of a rectangle that encircles the foundation and inertia moments of Ac around $X, Y$ and $Z$-axis.

Formulas for dynamic springs and dampers, $\bar{K}$ and $\bar{C}$, are widely known (e.g. Arya et al., 1979), a description of these formulae is beyond the scope of the

$$
\left.\begin{array}{ccc}
0 & 0 & 0 \\
0 & 0 & 0 \\
0 & 0 & 0 \\
m\left(4 B^{2}+A^{2}\right) / 12 & 0 & 0 \\
0 & m\left(4 L^{2}+A^{2}\right) / 12 & 0 \\
0 & 0 & m\left(4 L^{2}+4 B^{2}\right) / 12
\end{array}\right]
$$

present study. Once the values have been obtained we can calculate the dynamic spring and dampers as a function of the soil internal damping and the frequency of excitation by using the following equations:

$$
\begin{aligned}
& K(\beta)=\bar{K}-\omega \bar{C} \beta \\
& C(\beta)=\bar{C}+2 \bar{K} \beta / \omega .
\end{aligned}
$$

Expressions (25) and (26) are based on the viscoelasticity principle. For a general case, six pairs of equations like (25) and (26) should be calculated to represent the six degrees of freedom of the system, that is to say, $K v z(\beta)$ and $C_{v} z(\beta), K h y(\beta)$ and $C h y(\beta), K h x(\beta)$ and $C h x(\beta), K \theta x(\beta)$ and $C \theta x(\beta), K \theta y(\beta)$ and $C \theta y(\beta)$, and $K \theta z(\beta)$ and $C \theta z(\beta)$. These values are the input to arrange the stiffness and damping matrices shown here.

\section{Embedment depth influence on rigid foundation response}

This section presents an application of the previously developed formulation by doing a sensitivity study showing the effect of embedment depth on displacement and rotation response. Usually, block foundations for machinery are embedded in the soil from $H=0.20 \mathrm{~m}$ to $H=0.50 \mathrm{~m}$ depth. The effect of embedment depth in the response is by an increase of rigidity and damping thus, displacement and rotation amplitudes are reduced.

In some cases, damping due to embedment may be negligible however, the effect of the embedment depth is relevant to the spring stiffness values. Embedment depth could lead to operate a machine near to its resonance region and this could produce failure effects due to the force produced by the rotating components. 
Results of a sensitivity study showing the effect of the embedment depth in clay using the formulation developed here are presented in figures 3, 4 and 5. Relationships proposed by Arya et al. (1979) between superficial and embeded springs and dampers were used and are shown in table 2 . The formulas seen in table 2 show the relationship between the embedding coefficients
(Kend and Cemb) and the non- embedding ones (Ksup and Csup). The input data for soil, foundation and machine used in this study is presented in table 3. Coefficients for dynamic springs and dampers are also shown in table 4. represents the Poisson ratio used for the calculations.

Table 2. Relations between stiffness and damping for foundations surface overlying and foundations embedding

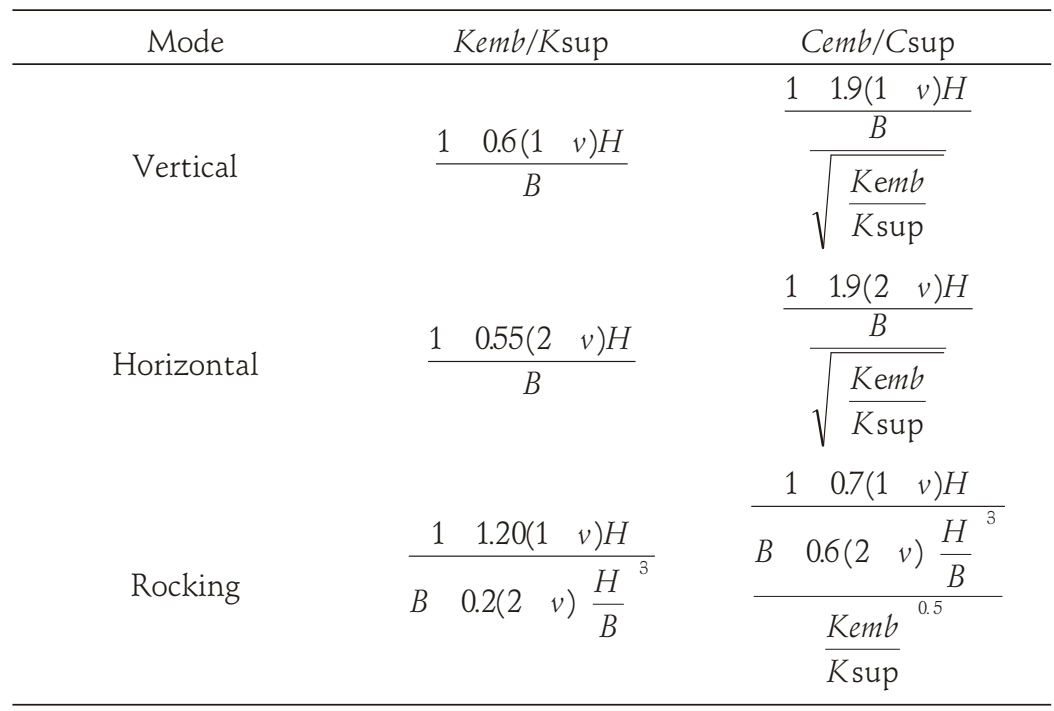

Table 3. Soil, Foundation and Machine data for the sensitivity study

\begin{tabular}{llll}
\hline \multicolumn{1}{c}{ Soil Data } & \multicolumn{1}{c}{ Foundation Data } & \multicolumn{1}{c}{ Machine Data } & \multicolumn{1}{c}{ Units } \\
\hline (internal damping) $=0.03$ & $\mathrm{~B}($ width $)=0.50$ & HIGH $=0.5$ & Tons. \\
(volumetric weight $)=1.6$ & $\mathrm{~L}($ large $)=1.00$ & WEIGHT $=2.5$ & Meters \\
$\mathrm{G}$ (shear modulus $)=14060$ & $\mathrm{~A}=0.50$ & MASROT $=0.015$ & Seconds \\
$($ Poisson ratio $)=0.33$ & $\mathrm{~L} / \mathrm{B}=2.0$ & EXCENTRIC. $=0.08$ & \\
Vs (shear speed $)=293.69$ & $\mathrm{H}($ embedding depth $)=$ variable & & \\
\hline
\end{tabular}

Table 4. Coefficients for dynamic springs and dampers for the embedment depth sensitivity study

\begin{tabular}{|c|c|c|c|c|c|c|c|}
\hline \multirow{2}{*}{ Coefficient } & \multicolumn{7}{|c|}{ Machine operation velocity (RPM) } \\
\hline & 500 & 1000 & 1500 & 2000 & 2500 & 3000 & 3500 \\
\hline $\mathrm{a} 0$ & 0.090 & 0.180 & 0.270 & 0.360 & 0.460 & 0.540 & 0.620 \\
\hline kvz & 1.000 & 1.000 & 0.990 & 0.980 & 0.970 & 0.960 & 0.940 \\
\hline khy & 1.000 & 1.000 & 1.000 & 1.000 & 1.000 & 0.995 & 0.990 \\
\hline $\mathrm{k} \theta \mathrm{x}$ & 1.000 & 0.995 & 0.980 & 0.960 & 0.940 & 0.925 & 0.915 \\
\hline$k \theta y$ & 0.980 & 0.950 & 0.920 & 0.890 & 0.860 & 0.850 & 0.820 \\
\hline $\mathrm{k} \theta \mathrm{z}$ & 0.990 & 0.995 & 0.980 & 0.975 & 0.960 & 0.945 & 0.940 \\
\hline cVz & 0.980 & 0.990 & 1.000 & 1.000 & 1.000 & 1.000 & 1.000 \\
\hline chy & 1.000 & 1.000 & 1.000 & 1.000 & 1.000 & 1.000 & 1.000 \\
\hline$c \theta x$ & 0.030 & 0.090 & 0.110 & 0.180 & 0.210 & 0.270 & 0.330 \\
\hline$c \theta y$ & 0.020 & 0.060 & 0.130 & 0.210 & 0.310 & 0.390 & 0.460 \\
\hline$c \theta z$ & 0.020 & 0.080 & 0.120 & 0.200 & 0.300 & 0.350 & 0.400 \\
\hline
\end{tabular}


DOI: http://dx.doi.org/10.22201/fi.25940732e.2010.11n3.024

Carbajal-Romero M.F., Rodríguez-Castellanos A., Rodríguez-Sánchez J.E. and Flores-Méndez E.

Results obtained from the embedment depth sensitivity study are as follows; figure 3 shows the influence of the embedment depth in the horizontal displacement "dy", it can be seen that the response of the system is highly controlled by the embedment depth and resonant peaks are observed at 2500 and 3000 RPM. Figure 4 shows vertical displacements " $\mathrm{dz}$ ", it is clear that for deeper embedments, vertical displacements are diminished. Finally, figure 5 shows that the embedment depth also leads to reduce the rotations.

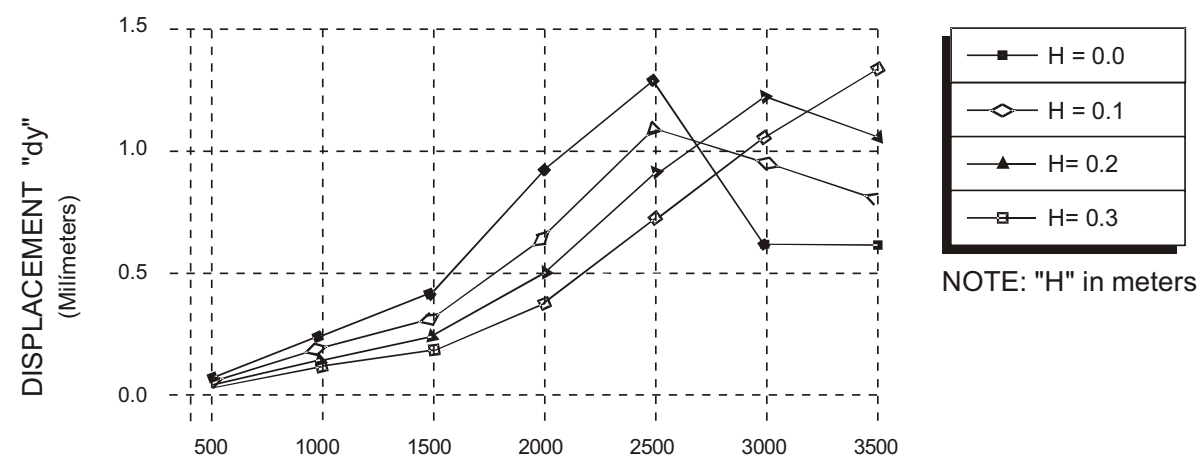

OPERATION FRECUENCY (R.P.M.)

Figure 3. Embedment depth influence on displacement 'dy'

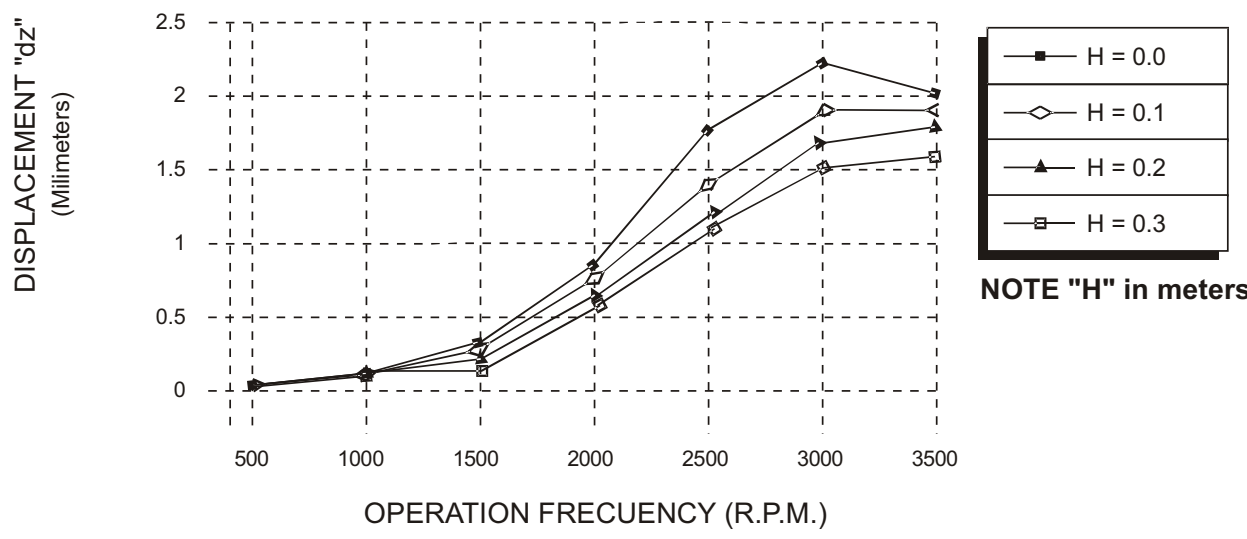

Figure 4. Embedment depth influence on displacement ' $d z^{\prime}$

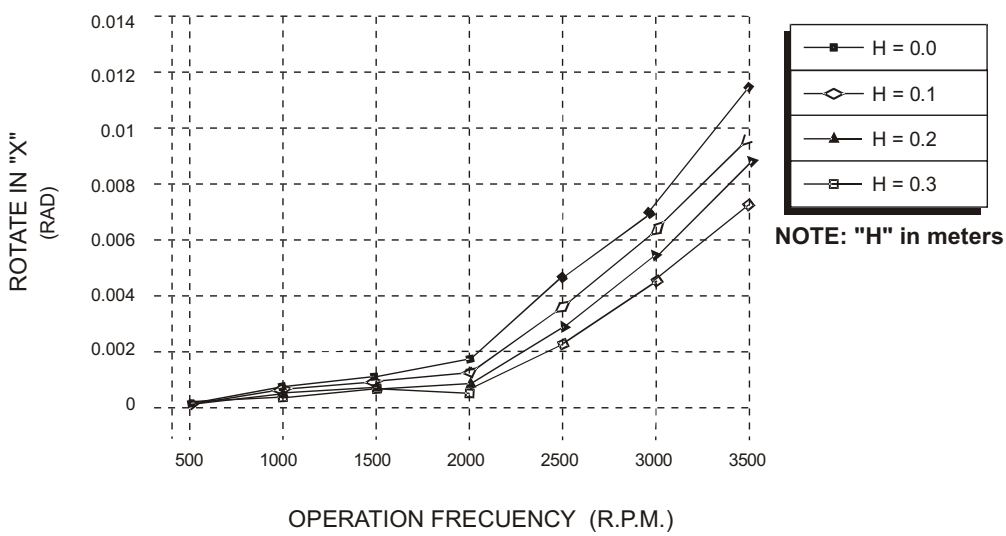

Figure 5. Embedment depth influence on rotation around ' $x$ ' 
DOI: http://dx.doi.org/10.22201/fi.25940732e.2010.11n3.024

Matrix Formulation of Foundations for Vibrating Machinery in Frequency Domain

\section{Conclusions}

The well known problem of a vibrating structure and its soil interaction response has been solved with a novel mathematical manipulation that leads to a formulation of multiple applications. These expressions allow determining the response of rigid bodies on elastic damped foundations considering the foundation restriction effects acting simultaneously in all directions; this means that a coupled displacement response considering six degrees of freedom is obtained. The response of the system in terms of displacements and rotations is determined for a defined set of frequencies. Thus, response can be compared with operational displacement and rotation limits. Moreover, this formulation may be useful for determining couple response of rigid foundations including the cases where springs or dashpots are not orthogonally oriented. The formulation is matrix based thus; it can be computationally programmed for industrial applications. As an application, the effect of embedment depth was determined in a sensitivity study and its relevant effects were pointed out.

\section{References}

Arya S.C., Ónell M.W., Pincus G. Design of Structures and Foundations for Vibrating Machines. Houston. Gulf Pub. Co. Books Division. 1979.

Bowles J.E. Foundation Analysis an Design. Fifth Ed. The Mc. Graw-Hill Companies, Inc. 1996.
Dobry R., Gazetas G. Stiffness and Damping of Arbitrary Shaped Machine Foundations. J. Geotech. Eng., 112: 109-135. 1986.

Dobry R., Gazetas G. Dynamic Stiffness and Damping of Foundations by Simple Methods. On: Proc. Symposium. Vibration Problems in Geotechnical Engineering, ASCE, 75-107.1985.

Gazetas G. Analysis of Machine Foundation Vibration: State of the Art. J. Soil Dynamics and Earthquake Engineering, 2:2-42. 1983.

Gazetas G. Formulas and Charts for Impedances of Surface and Embedded Foundations. J. Geotech. Engng., ASCE, 117(a):1363-1381. 1991.

Luco J.E. Linear Soil-Structure Interaction: A Brief Review. Earthquake Ground Motion and its Effects on Structures, AMD 53:41-57. 1982.

Richard F.E., Hall J.R., Woods R.D. Vibrations of Soils and Foundations. Nueva Jersey. Prentice Hall Inc, Englewood Clitts. 1970.

Pais A., Kausel E. Approximate Formulas for Dynamic Stiffnesses of Rigid Foundations. Soil Dynamics and Earthquake Engineering, 7:213-227. 1988.

Wolf J.P., Deeks A.J. Foundation Vibration Analysis: A Strength-of-Materials Approach. 1st Ed. Oxford. Elsevier Mass. 2004.

Wolf J.P., Paronesso A. Lumped-Parameter Model for a Rigid Cylindrical Foundation Embedded in a Soil Layer on Rigid Rock. Earthquake Engineering \& Structural Dynamics, 21:1021-1038. 2007.

Wu W.H., Chen C.Y. Simplified Soil-Structure Interaction Analysis Using Efficient Lumped Parameter Models for Soil. Soils and Foundations, 42:41-52. 2002. 
DOI: http://dx.doi.org/10.22201/fi.25940732e.2010.11n3.024

Carbajal-Romero M.F., Rodríguez-Castellanos A., Rodríguez-Sánchez J.E. and Flores-Méndez E.

\footnotetext{
About the authors

Manuel Faraón Carbajal-Romero. Obtained a BSc in electromechanical engineering at Instituto Tecnológico de Tehuacan, a MSc in mechanical engineering at Sección de Estudios de Posgrado e Investigación of Escuela Superior de Ingeniería Mecánica y Eléctrica of IPN and a PhD in mechanical engineering in Sección de Estudios de Posgrado e Investigación of Escuela Superior de Ingeniería Mecánica y Eléctrica in IPN. He works as investigating professor in Sección de Estudios de Posgrado e Investigación of Escuela Superior de Ingeniería Mecánica y Eléctrica at IPN unidad Azcapotzalco and he belongs to the National System of Investigators (SNI).

Alejandro Rodríguez-Castellanos. Obtained a BSc in civil engineering at Instituto Politécnico Nacional, a MSc in structural engineering in Sección de Estudios de Posgrado e Investigación from Escuela Superior de Ingeniería y Arquitectura in IPN and a PhD in mechanical engineering in Sección de Estudios de Posgrado e Investigación of Escuela Superior de Ingeniería Mecánica y Eléctrica at IPN. He works in the technological area of civil engineering in Instituto Mexicano del Petróleo and he is invited professor in Sección de Estudios de Posgrado e Investigación of Escuela Superior de Ingeniería Mecánica y Eléctrica in IPN unidad Azcapotzalco, where he lectures Numeric Methods and he belongs to the National System of Investigators (SNI).

Efraín Rodríguez-Sánchez. Obtained a BSc in Civil Engineering at Facultad de Ingeniería, UNAM and a PhD in Mechanical Engineering from University College London. Professionally he has collaborated at Instituto Mexicano del Petróleo in the area of marine platforms in the design disciplines, inspection and maintenance as well as in the planning of the development of fields in deep waters. At the moment he is the responsible for the technical area of operation and maintenance of systems in deep waters and belongs to the National System of Investigators (SNI).

Esteban Flores-Méndez. Obtained a BSc in Physics at Instituto de Física, UNAM. a MSc in structural engineering in Sección de Estudios de Posgrado e Investigación from Escuela Superior de Ingeniería y Arquitectura in IPN and a PhD in structural engineering in Sección de Estudios de Posgrado e Investigación from Escuela Superior de Ingeniería y Arquitectura in IPN. He works as investigating professor in Sección de Posgrado de Estructuras en la ESIA Unidad Zacatenco, IPN Unidad Zacatenco and associate professor in Instituto de Geofísica de la UNAM.
} 